\title{
Reconfiguring the Firm's Assets for Innovation
}

\author{
Dusan Schreiber ${ }^{*}$, Patricia Tometich ${ }^{2}$, Aurora Carneiro Zen ${ }^{2}$, Raquel Engelman ${ }^{1}$
}

\begin{abstract}
The innovation process and the generation of sustainable competitive advantage are permanently on the agenda in technology management. According to Teece (2007), one way to achieve a competitive advantage is to develop dynamic capabilities, a process in which the author identifies three moments: i) to perceive and shape opportunities and threats (sensing), ii) to grasp the opportunities (seizing), iii) to increase, to combine, to secure and, when necessary, to reconfigure the tangible and intangible assets. The aim of this paper is to investigate how the strategic internal changes were introduced to influence on developing the innovation capability in order to sustain and expand the competitive advantages of the firm. To do so, a case study was carried out in a firm that work within the furniture sector more than 30 years and took decision to increase its competitive advantage by investing in product design, what created conditions for the development of new capabilities. Interviews were conducted using questions that allowed the respondents to freely express their experiences and perceptions about the changes that have occurred in their sectors as a result of this process and was possible to identify the intensity of reconfigurations in capabilities that resulted from the creation of the Design Center.
\end{abstract}

Keywords: Dynamic capabilities; Innovation; Furniture industry.

Submitted: May 5 $5^{\text {th }}, 2019 /$ Approved: May $1^{\text {2th }}, 2020$

\section{Introduction}

The guarantee of earnings is related to the methods of organization and business strategies (Teece, 1986, 2006) and so it is important to explore the changes that occur within industries which allow them to constantly innovate. To remain competitive, companies must constantly reinvent themselves by developing skills that differentiate them from others, and to do so, they should maintain their dynamic capabilities (Teece, Pisano and Shuen, 1997; Eisenhard and Martin, 2000; Winter, 2003; Teece, 2007). Numerous studies involving dynamic capabilities have sought to understand how firms can sustain competitive advantages in environments where constant change is the norm (Teece, 2007). However, Zahra, Sapienza and Davidson (2006) highlight that the need to reconfigure or renovate routines may arise from internal motivations, with changes in the organizational conditions that do not necessarily relate to the competitive environment.

In this scenario, the aim of this paper is to investigate how the strategic internal changes were introduced to influence on developing the innovation capability in order to sustain and expand the competitive advantages of the firm. Based on Teece's (2007) proposal, which establishes three phases in the process of expanding the capabilities - sensing, seizing and reconfiguration - we sought to identify the changes in the company capabilities highlighted in Zawislak, Alves, Tello-Gamarra, Barbieux and Reichert $(2012,2013)$ as being drivers of the innovation capabilities, namely: the technology development capability, operational capability, managerial capability and transactional capability.

Zawislak, Alves, Tello-Gamarra, Barbieux and Reichert (2013) emphasize that innovativeness involves dealing with knowledge and technology in such a way that it allows the products generated in the process to be successfully placed on the market, thus going beyond the mere development of technological skills, which was highlighted by scholars such as Dosi (1988) and Lall (1992).

If, on the one hand, it is important to develop innovation capabilities, it is also necessary to be sufficiently integrated internally to enable a coherent arrangement of the capabilities involved in the innovative process. Although dynamic capabilities have been widely studied, the way they are developed and internally modified to achieve increased competitiveness in enterprises is still little explored. This study attempts to fill that gap by attempting to identify not only what it is that enables a company to innovate, but also the changes in its routines that will sustain its ability to create value and competitive advantage in the market over time. In order to achieve this objective were evidenced changes of the reconfiguration of the dynamic capabilities based on the the creation of the Design Center in a furniture industry, as in the technology development capability, operational capability, managerial capability and transactional capability. Several authors claim that this kind of approach is rare to be found in the scientific literature that study dynamic capabilities (Laaksonen and Peltoniemi, 2018; Hashim, Raza and Minai, 2018; Qaiyuma and Wang, 2018).

To do so, we conducted an in-depth case study, from November 2012 to December 2013, that involved three company visits and five interviews, using open-ended questions that were answered by those responsible for each of the different areas of the company. For this study, we selected the case of a furniture manufacturer, located in the south of Brazil.

Besides this introduction, the article is organized into four sections. First, the theoretical framework addressing firm capabilities and innovation is provided, which is followed by a description of the research method, and then the case is presented. Finally, the conclusions that can be drawn from the study and its limitations are presented.

(1) Universidade Feevale, Brazil.

(2) Universidade Federal do Rio Grande do Sul (UFRGS), Brazil.

*Corresponding author: dusan@feevale.br 


\section{Firm Capabilities and Innovation}

Innovation has been studied from various perspectives. Freeman (1994) and Alford (2018) point out that in the literature, the concept of innovation is associated with changes in processes and products involving the application of scientific and technical knowledge to solve production and marketing problems that result in profit.

This value building may be based on the knowledge accumulated by companies (skills, competencies and experience), reflecting an internal source of innovation, or may come from the adoption of innovations developed by others (Nelson and Winter, 1982; Lewin and Massini, 2003; Darawong, 2018; Beltagui, 2018). In either case, to innovate, a company needs to have internal capabilities and, in moreover, must possess the ability to constantly develop them (Schriber and Löwstedt, 2018).

In the literature, the term "capability" has been used in various forms, both to refer to human abilities (Penrose, 1959; Becker, 1962; Barney, 1991; Macphersona and Herbaneb, 2015; Teece and Leih, 2016; Krzakiewicz and Cyfert, 2017; Qaiyuma and Wang, 2018) and to define sets of skills, experience and accumulated knowledge within firms (Richardson, 1972; Felin and Powell, 2016; Fallon-Byrne and Harney, 2017; Hashim; Raza and Minai, 2018). Both perspectives converge in the sense of referring to the possibility of firms conducting their operations while remaining competitive in the market, using knowledge, experience and skills to offer solutions based on opportunities identified in the market, hence creating value by satisfying consumer desires. These are the capabilities that enable firms to develop in the dynamic market scenario and are identified in the literature in two pertinent theoretical approaches: technological capabilities and dynamic capabilities.

The technological capabilities approach considers a dynamic setting, but focuses on the creation, adoption and adjustment of the technological bases of firms so that they retain their competitive advantage (Bell and Pavitt, 1995; Lall, 1992; Teece and Leih, 2016; Beltagui, 2018). The understanding that the development of technology is a source of competitive advantage for companies is well-established in the literature (Lall, 1992, Bell and Pavitt, 1995; Kim, 1999; Afuah, 2002; Reichert, Beltrame, Corso, Trevisan and Zawislak, 2011; Qaiyuma and Wang, 2018).

Lall (1992) emphasizes the role of technological change as a continuous process in which technical knowledge is created and absorbed. For the author, in order to be competitive, companies need to have an investment capability, operational capability and the capability to interact with the economy. In a similar approach, Lall (1992), Bell and Pavitt (1995), Fallon-Byrne and Harney (2017), Laaksonen and Peltoniemi (2018) highlight the role of technical knowledge in firm performance. These authors draw attention to the difference between the knowledge needed to keep the company's regular activities functioning and that which allows it to change the technologies used. The term dynamic capabilities refer to an approach that considers a scenario of continuous change in which firms must constantly reinvent themselves to sustain a competitive advantage. Teece, Pisano and Shuen (1997), Schriber, S., Löwstedt (2018), Alford (2018) highlighted the role of the development of internal capabilities as being key to achieving and maintaining competitiveness in the rapidly changing technological environment. For these authors, considering the dynamic capabilities approach, "strategy involves choosing from among and committing to long-term paths or trajectories of competence development" (Teece, Pisano and Shuen, 1997, p. 529). This initial effort to describe the capabilities represented a way to understand the strategic changes (Helfat and Peteraf, 2009; Macphersona, Herbaneb and Jones; 2015; Krzakiewicz and Cyfert; 2017).

The dynamic capabilities were initially defined as the ability to achieve new forms of competitive advantage, and the term "dynamic" referred to the capability to renew competencies in order to keep pace with changes in the business landscape, and the term "capability" emphasized the role of strategic management in integrating, adapting and reconfiguring the knowledge, skills, competencies and internal and external resources, needed to meet the demands of the changing environment (Teece, Pisano and Shuen, 1997; Beltagui, 2018; Darawong, 2018). From a similar perspective, Eisenhardt and Martin (2000) and Laaksonen and Peltoniemi (2018) associated dynamic capabilities with the organizational resources, skills and competences.

Teece (2007) argues that to sustain a prominent position, companies constantly develop their dynamic capabilities, and, for analytical purposes, this process can be divided into three parts: i) perceiving and shaping opportunities and threats (sensing), ii) grasping opportunities (seizing), iii) increasing, combining, protecting, and when necessary reconfiguring the tangible and intangible assets. Augier and Teece (2009) argue that without these practices a company may experience a period of success in the market but will not be able to sustain that success in a competitive environment as it will be incapable of continuous innovation.

Several studies support the assertion that to be innovative, companies need to develop a set of skills (Macphersona, Herbaneb and Jones, 2015; Teece and Leih, 2016; Takahashi, Bulgacov, Bitencourt and Kaynak, 2017; Alves, Barbieux, Reichert, Tello-Gamarra and Zawislak, 2017). However, there is still no exact definition of what those capabilities are. Some researchers consider the existence of capabilities that have not yet been identified or described, which indicates there is space to deepen the research so as to increase our understanding of innovativeness in firms (Burgelman, 1994; Christensen, 1995; Guan and Ma, 2003; Yam, Tang and Lau, 2011; Zawislak, Alves, Tello-Gamarra, Barbieux and Reichert, 2012; Zawislak, Zen, Fracasso, Reichert, and Pufal, 2013; Beltagui, 2018; Darawong, 2018; Schriber and Löwstadt, 2018).

Some researchers have based their work on models that seek to explain the innovation capability (Lawson and Samson, 2001; Terziovski, 2007; Zawislak, Alves, Tello-Gamarra, Barbieux and Reichert, 2012; 2013). The model from Zawislak, Tello-Gamarra, Alves, Barbieux and Reichert $(2012,2013)$ divides the innovation capability of firms into four capabilities: 
1. Technology development capability, defined as the ability to interpret the state of the art, absorbing and transforming a given technology to create or change its other capabilities (operational, managerial and transactional) with the aim of achieving higher levels of technical and economic efficiency;

2. Operational capability, described as the ability to use a given production capacity in the conduct of daily routines that involve knowledge, technical systems and skills in a given time;

3. Managerial capability, indicated as the company's ability to transform technology into a coherent operational and transactional arrangement.

4. Transactional capability, defined as the ability to reduce transaction costs, involving market transactions, whether with customers or suppliers.

This research uses the above-definitions, suggested by Zawislak, TelloGamarra, Alves, Barbieux and Reichert $(2012,2013)$, to address the reconfiguration of capabilities, assuming that their development is reflected in the innovative performance, since for firms to sustain the innovation capability, changes should occur in their internal routines. Based on what Teece (2007) called sensing, seizing and reconfiguring, an event was identified in which the studied company sensed and seized an opportunity, developing and reconfiguring its ability to widen its competitive advantage. In Figure 1, is the model of this study that sets out these relationships between the capabilities, assuming that evolution and development may occur in those capabilities whenever a company makes strategic decisions directed towards innovation.

To measure the changes in capabilities, the respondents participating in the case study were asked to rate some activities before and after the studied decision. That rating employed indicators used in the literature, as shown in Chart 1 and was provided by four of the five professionals interviewed (since one of them had not worked for the firm during the earlier period) and offered the alternatives low, medium and high for each of the indicators presented.

Figure 1. Reconfiguration of innovation capabilities. Source: Adapted from Teece (2007); Zawislak, Tello-Gamarra, Alves, Barbieux and Reichert (2012),

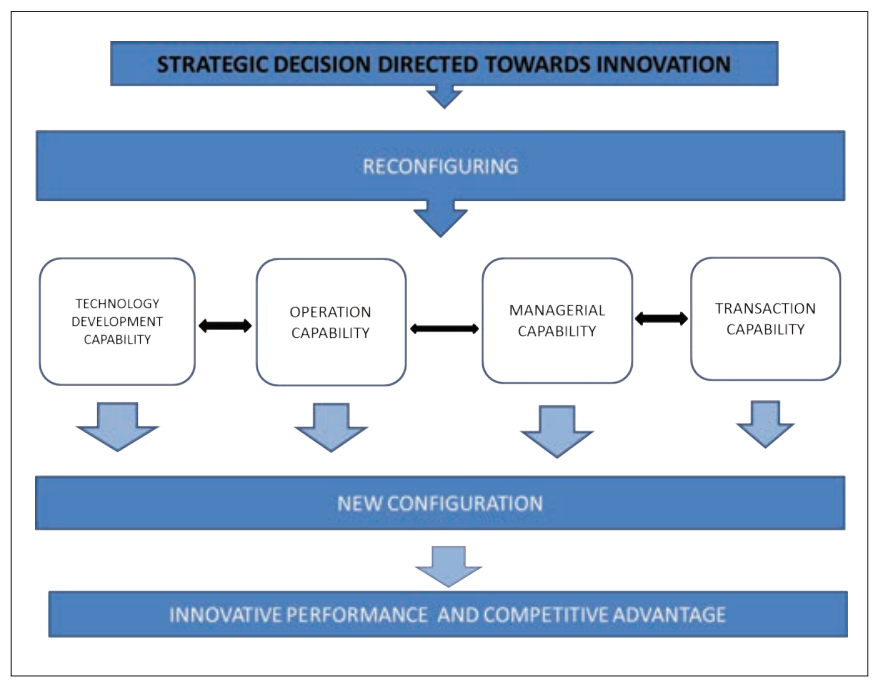

Chart 1. Analytical categories and corresponding theoretical bases.

\begin{tabular}{|c|c|c|}
\hline Category & Main idea & Theoretical base \\
\hline $\begin{array}{c}\text { Technology } \\
\text { development } \\
\text { capability }\end{array}$ & $\begin{array}{l}\text { Acquisition, imitation, adap- } \\
\text { tation, modification and de- } \\
\text { velopment of knowledge and } \\
\text { technical systems for internal } \\
\text { application in products and pro- } \\
\text { cesses. }\end{array}$ & $\begin{array}{l}\text { Lall, 1992; Bell and } \\
\text { Pavitt, } 1995\end{array}$ \\
\hline $\begin{array}{l}\text { Operational } \\
\text { capability }\end{array}$ & $\begin{array}{l}\text { Quality control; flexibility in the } \\
\text { production process; continuous } \\
\text { improvement actions; inventory } \\
\text { management; just-in-time prac- } \\
\text { tices, pull production. }\end{array}$ & $\begin{array}{c}\text { Chandler, 1990; Hayes } \\
\text { and Pisano, } 1994\end{array}$ \\
\hline $\begin{array}{l}\text { Managerial } \\
\text { capability }\end{array}$ & $\begin{array}{l}\text { Integration between the areas } \\
\text { of the company; establishing } \\
\text { and monitoring goals and ob- } \\
\text { jectives; existence of formal } \\
\text { rules and procedures; relative } \\
\text { autonomy in decision making } \\
\text { within hierarchical levels, the } \\
\text { development and management } \\
\text { of human resources; investment } \\
\text { policies. }\end{array}$ & $\begin{array}{l}\text { Penrose, 1952; Bar- } \\
\text { nard, 1966; } \\
\text { Mintzberg, 1973; } \\
\text { Chandler, } 1977\end{array}$ \\
\hline $\begin{array}{c}\text { Transactional } \\
\text { capability }\end{array}$ & $\begin{array}{l}\text { Relationships with customers } \\
\text { and suppliers, distribution, lo- } \\
\text { gistics, negotiations, contracts, } \\
\text { trademark and outsourcing. }\end{array}$ & $\begin{array}{l}\text { Coase, 1937; William- } \\
\text { son, 1985; } \\
\text { Argyres, 1996; 2011; } \\
\text { Madhok, 1996; Lan- } \\
\text { gois and Foss, 1999; } \\
\text { Mayer and Salomon, } \\
\quad 2006\end{array}$ \\
\hline
\end{tabular}

Chart 1 following a strategic decision intended to facilitate innovation.

Below, the case of a company in the furniture industry is presented which allows the analysis of the recombination and reconfiguration that has occurred in each of the four capabilities.

\section{Method}

The theoretical implications that strategic shifts represent for the development of a company's capabilities are complex and dependent on specific contexts. Thus, statistical analyses that use a large number of data were not considered as best option in this research. Therefore, to achieve the aim of this research - to better understand the process of capability development - we considered more appropriate to carry out an in-depth case study, following the strategy proposed by Yin (2010). The first step was to conduct a literature review in search of a theoretical framework to guide the collection and analysis of the empirical data. Thus, this study sought to understand the reasons, forms and actors involved in the reconfiguration of the capabilities in a firm following the decision to implement a strategic shift.

The furniture company, here referred to as 'Furniture', was chosen due to an easily identifiable strategic decision to introduce a Design Center, although the company was, until then, characterized as producing standardized items. 
During data collection, we sought various sources of evidence, such as in situ observations, the review of documents and web sites, but mostly by reiterating the same questions with several interviewees to ensure convergent information. Additionally, a scale was used, in which the respondents rated the performance of their areas before and after the decision to invest in design.

The study was conducted during 2013. Three visits were made to the company and seven interviews held with five people, that were chosen following main criteria as being responsible for one of the organizational area dealing with the researched dimensions: management, operations, technology development or transactions. The first interview was part of the case selection process and had the goal to identify the moment the company realized an opportunity (sense) and made its strategic decision (seize) aimed at innovation. The other six interviews aimed to observe the process of capability development (reconfiguring) Those interviews were conducted using open-ended questions (Apendix) that allowed the respondents responsible for each of the different areas of the company to freely express themselves. A scale was also used in which the interviewees rated the performance of the areas before and after the strategic decision selected for this study. Number of interviews were considered enough, following the principle of saturation, of Eisenhardt (1989), that recommend to stop when data are becoming redundant.

The interviews were recorded and transcribed using established categories described in Chart 1 of section 2 and content analysis (Bardin, 2011) was performed to identify any changes and reconfigurations that occurred in the company's capabilities. This analysis was made by authors of the research, through reading text of the interview and highlighting aspects related to the categories technological development, management, operations and transactions.

\section{A case of 'Furniture' company}

The studied company, 'Furniture', started out as an exporter in the retail market and is now present in over 60 countries, having pioneered the export of Brazilian furniture in the mid-1970s. Around 40 years in the market, Furniture has, to date, eighteen patents pending in Brazil. It is a family business that, since its foundation, has retained the characteristic of looking for market opportunities. For this research, we examined the introduction of a Design Center within Furniture's manufacturing complex.

The decision to invest in design for innovation was taken to avoid the situation of price competition in the retail sector, with the idea of selling products with greater added value in the different markets it serves. This decision was taken in the early 2000s, and to achieve it the company established a partnership with a recognized Italian design center. In 2005, Furniture opened the Design Center installed within its manufacturing complex.

Next, we are presenting the details about the changes that occurred during this process with regard to each of the company's capabilities. A descriptive language is used to illustrate the changes that occurred with the implementation of the strategy under study.

\subsection{Technology Development Capability}

The scale designed to assess the Technology Development area before and after the introduction of the Design Center showed there was an increase in the technology development capability. Just one of the interviewees thought that one of the indicators, 'modification and development of knowledge' had remained stable, since it had always been high.

Before the construction of the Design Center, product development was not organized as such. When creating a new product "half a dozen people" used to be called together to make a product, and each one did their part. This led to the need for reworking due to the lack of integration in the process, and finally, because of the lack of synchronization in the creation, factors that needed to be modified were perceived.

The project to build Furniture's Design Center began in 2005. In the first phase the professional responsible for the project spent a month getting to know the various areas/sectors within the company and particularly how the production process functioned, after which he designed the Design Center itself.

He accompanied the building work which took about three months. In the following two months, during which he was getting to know the company, he worked on product development in an office located within the engineering area. At that time design was secondary, it was seen as being superficial - its role was merely to "embellish" the products.

Because the company manufactured standardized furniture for sale in large retail stores, the company had little opportunity to attempt designs, since the products were designed according to the customers' order which specified what they wanted and how much they would pay. Thus, it was necessary to show something different within that limitation. However, the Italian institution, which was a partner in the project, identified that Furniture was well structured to cater to that particular market. Primarily, it was necessary to stimulate the appreciation of design, since the company directors had decided it was time to seek an alternative path for the business.

Design culture was gradually assimilated through the exchange of experiences in a process described by one interviewee as coming to understand: "Why they are talking about design?" and "What is design?" In the beginning, workshops were held that dealt with several products without any commitment regarding the products necessarily being produced by Furniture. In a workshop held in 2006 over a hundred projects were generated. These were described as a pool of ideas to work with, whether they are used or not in the future.

After this period of assimilation, which lasted for about two years, the Design Center was opened and they began to think about real products. This phase was described as an internal evolution in which the influence of the Design Center gradually grew until it was able to meet the objectives set in terms of product development. Hence, this process of diffusing innovation culture in the company enabled Furniture to launch two new brands. 
In 2008, the first new brand (here called brand A), with a completely different concept compared with Furniture's traditional product, was released, fitted furniture, being sold in exclusive shops and targeted at a high-income public. After the launch of brand A, due to the income growth among the Brazilian middle class, in 2010, Furniture launched brand $\mathrm{B}$, also specializing in fitted furniture, but targeted at the rapidly expanding medium-income public.

An interviewee points out that while Furniture had expertise in making furniture, its solutions were focused on the factory, and so failed to consider product variations and how the product would communicate and appear within a system.

Product development has become an ongoing process. Every week, at least one meeting takes place which includes representatives from each of the company's areas: management, sales, purchasing, production and development. The products are considered by the group, and discussions are held to align everyone's needs. When an idea is launched, the design, cost, target market and production process are considered, and each participant expresses its perception. This level of integration has improved the organization of product development.

Because of the meetings, the various products that are developed do not necessarily go straight to the market. Furniture uses the Italian expression "innovazione a scaffale" (English translation - 'innovation in the drawer'), which describes the practice of storing developed products for future opportunities.

Today, this center is in a phase that involves educating its public. One interviewee declared that the market is not always ready for innovation, and that today, part of their work is to pass on knowledge to their distributors, the public that is in the market representing Furniture. He points out that in the beginning the Design Center was only concerned with developing products, and that now it disseminates knowledge to those who represent it. This is being done through training programs offered at the Center. The interviewee says that it takes time for the market to assimilate changes because "the innovation only occurs when the developed product is in the client's home".

There are constant changes in the Design Center's routine. After spreading the culture of innovation throughout the company and keeping all the areas engaged in and integrated with product creation, the Center has reached internal maturity.

Today, the spreading innovation among the distributors is also part of the Center's activities. That way, the knowledge developed is carried to the market because, in the words of one interviewee creation may not be accepted: “(...) because one person who has insufficient knowledge to say something's right or not, and that person simply tells you no, then you have to have the courage to say, no, I will continue (...) because we cannot demand that the market has the same knowledge that we put there". In other words, for the success of Furniture, it is necessary to 'teach' the market.

\subsection{Operational Capability}

The scale designed to assess the capabilities showed a significant increase in the Operations area. There was already a good level of efficiency and quality, which improved even more, while flexibility was another point that showed improvement.

Prior to the creation of the fitted furniture brands, the routine in the factory allowed to increase speed of the production in relation to the production of one type of product over a long period of time. The factory used to spend almost a whole year producing the same model, while today a many different products are launched. Therefore, there was a need to adapt to this new situation. The factory began to need more flexibility, and it was necessary to separate it into two parts: one for the continuous production of the products for the standardized furniture brand sold in retail stores around the world, and another to manufacture fitted furniture items, which involves a completely different process from the former. Today, the engineering department details the process that each piece will pass through, in the factory. The company uses bar-code technology that allows the machines to be adjusted automatically.

In addition to the internal aspects and the changes that were necessary because of the new products, the technology in terms of machinery and tools that are available in the industry have been developing rapidly and Furniture is constantly upgrading. An interviewee mentioned that he attended the Hanover Fair in Germany in 2013 and realized that the company is now using some of the most modern machines in the world for the furniture sector. The only technology that it is not yet using is robots, a fact he attributes to the cost/benefit relationship between machine and human workforce in the current Brazilian situation.

Precision is characteristic of fitted furniture, and the company needed to hire two more people when production started, while other employees from the operational area received training for the new factory. There are, therefore, employees who work in both factories, according to the company's need.

All the 5 interviewees highlighted the increased demand from the large retailers for the mass volume product at the end of the year. Therefore, Furniture works with stocks of raw materials and finished products to meet this seasonal demand. Thus, the mass retail furniture is constantly being produced, while the fitted furniture is produced as the design lines are sold.

Therefore, there was an increase in the variety of products, and the major change in the area occurred in the organizational culture. Prior to the change in the product development process there were sixteen thousand items listed for the production in the company, today there are two hundred and fifty thousand items. The quality control has been modified, because now, in the case of the fitted furniture, it is the responsibility of each worker to "ask himself if he would accept it for himself, before passing part forward". 
The integration that exists today in product development is very important. One interviewee mentioned that when he received a differentiated design for an item of fitted furniture he thought, "how's a thing like this going to stand up?". Once the prototype was complete - which stood up - he says that there was a change of perception on the part of the engineering department.

Product quality has increased because the fact that fitted furniture requires pinpoint accuracy has also influenced the production of the standardized furniture for the mass retailers.

\subsection{Managerial Capability}

The scale designed to assess the Management area indicates that this capability remained stable, which can be attributed to both the family business culture and to the fact the capability was well developed prior to the event being studied here.

The interviewee, that provided information about this capability, believes that the company is now starting to enjoy the results of the investment made in the Design Center, which should be consolidated in the medium and long term. For him, the big change is related to the control and distribution of products and the value created by holding brands: "I have direct contact with the final consumer at the far end, and this allows me to create brand value much more easily. Likewise, it is possible to turn everything bad and suffer, but there is everything that contact at the end point offers." In the assessment of this professional, in retail stores, sales are targeted according to price and payment terms, and the final consumers in those stores do not pay attention to the brands of the products they buy: "Before you could say there was no brand. Even today, the person goes to the Store (...) to buy a dining room set, she does not think about the brand she's buying."

The company strategy has been maintained, although the form of management has been gradually modified to allow a relative decentralization of decision making. The knowledge that has been developed over time has provided the professionals in the company with the opportunity to grow "due to this change in culture, the idea of encouraging creation, ideas, innovation, of putting these professionals in contact with experts in the subject, of pushing them a little more."

It's worth to note that investments in innovation were between 5 and $10 \%$ of the gross revenues of the company between 2008 and 2012 and the interviewee suggests that the trend is that the percentage will stabilize at between 3 and 5\% in the coming years. This investment is concentrated on services "in people, consultancy, the work of designers, professionals, of agencies.”

The company's investment policy is planned considering a threeyear timeframe. An amount is set and the layout and machinery to be acquired are presented. Investments in machinery are periodically reviewed, because it is a very dynamic area, "they have ideas, thinking about the future, but the investments in machines which are the heaviest and most important, undergo changes over time. There are meetings twice a year that we call the seminars." During these seminars they think about the future of the factory.
Furniture's investments are made with its own resources, even with the huge supply of credit available from the banking system, which includes special credit lines subsidized by the government to promote and improve domestic industry. According to an interviewee, this organizational culture comes from the foundation of the family's first company. However, he says that they have assessed some offers, but there was no need for credit due to the company's pattern of gradual growth: "the company is not making leaps of $150 \%$ growth because that's not the idea. The growth has been gradual, so there hasn't been a great demand for cash, there's been no need to look for credit."

Net profit grew between 18 and 22\% per annum between 2008 (the year brand A was launched) and 2012. In 2012, Furniture launched 25 new products, which were responsible for $22 \%$ of its gross revenue in the same year. It should be said that although the company operates in more than sixty countries, exports account for around $20 \%$ of its revenues.

\subsection{Transaction Capability}

The scale designed to assess the Transactions area showed there was an increase in this capability. Moreover, the open questions in the interviews and other collected data suggest very significant changes took place in the area. The decision to invest in design resulted in two new brands, catering to different markets and involving a different sales structure. As with the operational area, it was necessary to create structures to support the new brands, so it is an area that has undergone significant changes.

This area of transactions involves both suppliers and customers, so members of the purchasing and the sales departments were interviewed.

Prior to the introduction of the Design Center new materials etc. were offered by the suppliers and together the management and operational teams decided what would be adopted by Furniture. With the presence of the design professionals, new ideas are developed internally which means that it is sometimes necessary to find new suppliers, so now there are purchase demands whereas before they merely bought what was offered.

The relationship with suppliers is, in general, long-term, since there are materials such as glass, which are constantly used. Although there are prerequisites for the development of suppliers, the sector in Brazil has not evolved much compared to other supply chains, such as the automotive chain. There are still many small businesses that are not equipped for large-scale business.

Regarding outsourcing, Furniture has retained its characteristic of hiring partners to perform services that are not within its own area of expertise. Any service that is not the focus of the company is contracted out, if the price is competitive, to avoid internalizing services that would probably provide poorer results if carried out by the company itself.

One of the interviewees believes integration was always present, as it is a prerequisite for the functioning of a company, and what happened was that the way of organizing the integration changed. He points out 
that there are companies that are very departmentalized, which in his view hampers the processes. Meanwhile Furniture avoids problems by having a product creation routine involving representatives from all the areas: "there is no point creating something that will only become a problem later."

Regarding transactions with suppliers, the relationship has become more difficult because Furniture is creating a lot and the suppliers are not able to keep up, so they often need to "teach" the suppliers.

About the transactions with customers, in an interview reference was made to the difficulty in providing information about what happened before the construction of the Design Center and the interviewee stated that the existence of the Center demonstrates professionalism in relation to the customers: "What I can tell you is that today, because we have the Center, we can provide the customer with a greater sense of confidence." There have been changes that have resulted in enhanced responsiveness, which is highly valued by the market, "when I joined the company we still used photographs of the products, today we have the design in $3 \mathrm{D}$ and we do everything on the computer, so I can tell you that it provides an agile, more professional response."

The agility mentioned here, is related, not only to the digital drawing technology, but also to the previously mentioned innovazione a scaffale' system. When the customer needs something, Furniture often has something ready or that can be easily adapted, to cater to that need, therefore, the company is seen as a problem solver by its retail customers. The customer specifies the type of product they need, and based on that requirement, Furniture can quickly present a proposal. The interviewee highlights the importance of the Design Center with a case that occurred the day before the interview: it concerns a customer that has 700 stores who presented their requirement by phone: "hey, I need a product like this, to sell at such a price, I will buy so many thousand pieces." In addition to the library of developed products, the flexibility and agility of the company's modern manufacturing facilities are important for this type of demand, since this customer placed his order in the same period that the company intended to conduct its own special sales activity.

Furniture has no problems with delays because the company is capitalized and working with stocks of essential raw materials as well as finished products that are in constant demand. This is a major competitive advantage for the company, as any competitor trying to enter the retail market has difficulties in delivering the quantity required by the stores that traditionally concentrate their orders for delivery at the end of the year.

The decision to invest in design was a way of meeting the challenge of making the transition from an economy based on low cost to one driven by innovation. They reported that at the beginning, the company focused on costs and inputs, then they began to invest in efficiency and scale, and the challenge then was to invest in creating value and uniqueness, which is the stage Furniture is currently at and is organizing itself to sustain in the future. In this changing scenario, the company came to see investment in design as being necessary to achieve higher levels of competitive advantage and has come to influence the market. It was pointed out that the way the company created value had changed with the inclusion of intangible traits that was made possible by the creation of new brands and by aggregating services to the products.

The main result of investment in the Design Center was the aforementioned creation of two new brands, sold in niche markets that are completely different from the traditional retail market with which Furniture is very familiar and in which it still operates. Both brands offer fitted furniture, the first one, launched in 2008, directed at the social-economic Class A, is sold in exclusive shops. Noting the market opportunities resulting from the growing number of people in the middle class in Brazil, in 2010, Furniture launched another brand of furniture directed at the upper-middle class, also sold in exclusive stores.

Furniture has different teams to manage the sales of each brand, however, due to the internal integration that is widespread in the company culture, people from different teams do not fail to identify opportunities related to each of the brands, by exchanging information among themselves. Regarding sales to the retailers, the company stands out for its agility in the production and capacity to deliver large volumes, and now with respect to the fitted furniture brands, sales are being directed towards investors willing to build exclusive shops to distribute Furniture's products, so the market approach is completely different.

\subsection{Analysis of case}

Furniture had sound finances, was well placed in the retail market and maintained a modern well-equipped manufacturing facility. While the company had a history of innovation, the process of creating and developing products was not formally organized. To sustain their prominent positioning, companies constantly develop their dynamic capabilities (Teece, 2007) and in Furniture this development process can be seen to have followed the steps outlined by Teece (2007): i) innovation with own design (sensing); ii) investment in creation of the Design Center (seizing); iii) developing knowledge about design, organizing a product development routine including all the company's areas, spreading the innovation culture; registering patents (reconfiguring).

Figure 2 shows the evolution of the process of developing the dynamic capabilities that occurred in Furniture, as described by Teece (2007). At the end of the process, the company has enhanced its performance and widened its competitive advantage.

Teece, Pisano and Shuen (1997) and Teece (2007) point to the reconfiguration of internal capabilities, but they do not describe which capabilities they are. For this reason, and considering that the strategic decision selected for the study involves innovation, the analysis resulting from this research has focused on the capabilities described in model proposed by Zawislak, Tello-Gamarra, Alves, Barbieux and Reichert $(2012,2013)$, which understands that innovativeness in firms occurs as a result of the combination of four capabilities: technology development, operational, managerial and transactional. 
Zahra, Sapienza and Davidson (2006) believe that the capabilities of the companies are "substantive" and what defines "dynamic capabilities" are the changes that occur in the substantive capabilities. In other words, the technology development, operational, managerial and transactional ca- pabilities are not dynamic, but the dynamic capability lies in the ability to modify each of these capabilities. Therefore, this study has sought to identify a strategic decision and compare the capabilities before and after that decision in an attempt to capture this dynamic process.

Figure 2. The process of developing dynamic capabilities at Furniture.

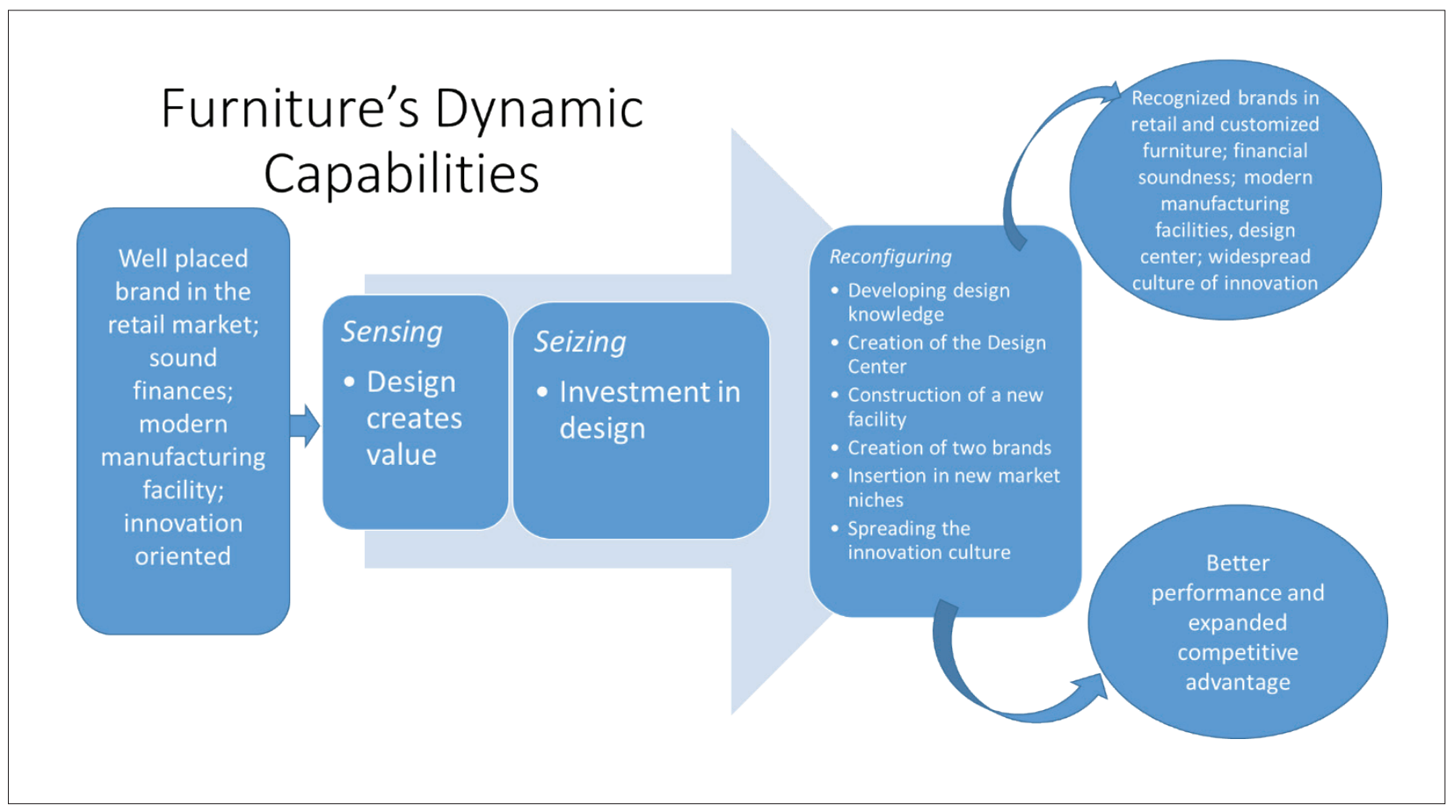

Analysis of the collected empirical data indicates that the management area underwent fewer changes in the process of reconfiguring the studied capabilities. It is likely that this is due to the family business culture, but it should also be recognized that the management capability of the company was already developing prior to the decision to pursue design in order to foster innovation and increase the company's competitiveness. However, the level of integration existing among the technology development, operational, management and transaction areas was instrumental in the reconfiguration process. The interviewees understand that there has always been integration, therefore it can be stated that the integration reached in order to develop innovations was a result of the knowledge gained during the process, by contracting both a renowned international Italian institute specializing in design and a full-time in-house design specialist. Furniture can be described as a company with an outstanding managerial capability that in the process of investing in design has reached the top level in innovation management.

The indicators found in the literature to assess management were the integration between the areas of the company, the establishment and monitoring of goals and objectives, the existence of formal rules and procedures, relative autonomy in decision-making within the various hierarchical levels; human resource development and management, and investment policies (Penrose, 1952; Barnard, 1966; Mintzberg, 1973; Chandler, 1977; Felin and Powell, 2016; Krzakiewicz and Cyfert, 2017; Takahashi, Bulgacov, Bitencourt and Kaynak, 2017).
Among these, there was progress in terms of integration with respect to product development, and a modest alteration in autonomy for decision making, but there was no change in the other studied items.

The operations area was also very well organized, but the modifications and changes are noticeable, with a considerable enhance the production capability that can be directly related to the development capability. In his interview, the director of the Design Center recalled that the diagnosis of the Italian consultants pointed out that the company was well structured to do what it was doing. Throughout the process it was also necessary to hire and train personnel for the production of the furniture for brand A, and this knowledge was also used in the launch of the brand B. The manufacturing plant that produces fitted furniture is separate from that which produces retail furniture and was built during the process. Investment in machinery and equipment has always been constant, because according to the general management the head of operation an up-to-date manufacturing facility is the minimum required to stay the market. In this sense, the observable change is related to the spread of the innovation culture that leads the operational staff to think about different applications for tools and hardware.

With respect to the operational capability, we identified an average degree of reconfiguration, which was mainly due to the increased production flexibility as well as its improved quality (Chandler, 1990; Hayes and Pisano, 1994; Laaksonen and Peltoniemi, 2018; Schriber and Löwstedt, 2018) following the creation of the Design Center. 
To evaluate the changes in the transaction capability, the following items were considered: relationships with customers and suppliers; distribution; logistics; negotiations; contracts; brand and outsourcing (Coase, 1937; Williamson, 1985; Argyres, 1996; 2011; Madhok, 1996; Langlois and Foss, 1999, Mayer and Salomon, 2006). A high degree of change was found in each item, indicating that considerable reconfiguration occurred in this capability. This result corroborates the arguments of Tello-Gamarra and Zawislak (2013) who suggest the transaction capability is the "missing link" in innovation, since technological development alone is insufficient to explain the phenomenon of innovation.

As Furniture maintained its operations in the business of providing furniture to retailers, the company's transactions have expanded. The type of negotiation is different, while the retail brand is sold through contacts with large chain stores and department stores, the fitted furniture brands are sold in exclusive shops, and so the business contact is with investors who will be store owners. The commercial approach to sales is different and made by professionals specifically dedicated to each market niche. Moreover, the market is not always prepared to absorb what is new, and therefore Furniture has assumed the role of "educator" by providing information to the distributors who represent it.

In terms of transactions with suppliers, the difficulty for them is to keep up with the needs of the company, which is also the case when creating differentiated products, and the establishment of a supply chain that can meet Furniture's expectations seems to be a major challenge.

A high degree of reconfiguration was found in the technology development capability, most notably in the internal construction of knowledge (Lall, 1992, Bell and Pavitt, 1995) seen in Furniture after the creation of the Design Center.

Since its foundation, Furniture has been a company that developed products, but there was little or no organization or integration in this task, as it was sporadic and often required reworking. The development capability grew significantly and required the development of the company's other capabilities, in particular the operations and transaction capabilities. In this sense, it is observed that when there is investment to develop a specific capability, the other company capabilities undergo alterations, modifications and/or extension.

After analysing the changes that occurred in each of Furniture's capabilities, it was possible to identify the intensity of reconfigurations in each one resulting from the creation of the Design Center, as is summarized in Chart 2.

Chart 2. Synthesis of the reconfiguration of furniture's capabilities intensity of the reconfiguration.

\begin{tabular}{c|c|c|c}
\hline Capabilities & High & Medium & Low \\
\hline Technology development & $\mathrm{X}$ & & \\
\hline Operational & & $\mathrm{X}$ & \\
\hline Managerial & & & $\mathrm{X}$ \\
\hline Transaction & $\mathrm{X}$ & & \\
\hline
\end{tabular}

\section{Conclusions}

Knowledge must be in constant development (Teece, 2007). Dynamic Capabilities have been studied over two decades, however, the way they are developed remains obscure due to the lack of elements that could enable this analysis. This study assumed that companies have dynamic capabilities that differentiate them, and that when they are in motion, they are responsible for increasing the competitive advantage. It was possible to observe the changes in firm's capabilities and to better understand the process of sensing/seizing/ reconfiguring by using the work of Zawislak, Tello-Gamarra, Alves, Barbieux and Reichert (2012, 2013). Combining Teece's (2007) theory with the work of Zawislak and colleagues $(2012,2013)$ this case study was a first effort to open the black box of dynamic capabilities, observing the firm's capabilities development and realizing an interdependence between them that allowed to elaborate the following theoretical propositions:

P1: Increasing the technology development capability of a company positively influences the reconfiguration of its operational capability.

P2: Increasing the technology development capability of a company positively influences the reconfiguration of its transaction capability.

P3: Increasing the technology development capability of a company positively influences the reconfiguration of its managerial capability.

P4: The substantive capabilities of companies exert positive influences on each other in the reconfiguration of their internal processes.

The results of this research contribute to the literature by initiating a thorough investigation of the movements in processes involving the reconfiguration of capabilities that are shown to be essential for the continued innovation and expansion of sustainable competitive advantage in companies.

The main limitation of the research is the inability to conduct a longitudinal study that would identify the problems that arise, and the measures taken to solve them. The analysis of a single case in which there was a single investment decision regarding a specific capability is also a limitation. Future studies can analyse investment decisions in the development of other capabilities in order to make comparisons and identify the influence of the changes in one capability on the others. It is also suggested that similar studies be undertaken using the longitudinal method.

\section{References}

Afuah, A.N. (2002) Mapping Technological capabilities into product markets and competitive advantage. Strategic Management Journal, 23, pp. 171-179.

Alford, P. (2018) Understanding collaborative innovation from a dynamic capabilities perspective. International Journal of Contemporary Hospitality Management. vol. 30 No. 6, pp. 2396-2416 Emerald Publishing Limited 0959-6119 DOI 10.1108/IJCHM-08-2016-0426 
Alves, A. C.; Barbieux, D.; Reichert, F. M.; Tello-Gamarra, J.; Zawislak, P. A. (2017) Innovation and Dynamic Capabilities of the Firm: Defining an Assessment Model. RAE, São Paulo, v. 57, n. 3, maiojun, 232-244.

Argyres, N. (1996) Evidence on the role of firm capabilities in vertical integration of learning and transaction cost perspectives. Academy of Management Journal, 17(2): pp. 129-150.

Augier, M; Teece, D. (2009) Dynamic Capabilities and the Role of Managers in Business Strategy and Economic Performance. Organization Science 20(2): pp. 410-421.

Bardin, L. Content analysis. São Paulo, SP: Edições 70, 2011. 279

Barnard, C. (1966) The Functions of the Executive. Harvard University Press, Cambridge.

Barney, J. (1991) Firm resource and sustained competitive advantage. Journal of Management, 17 (1): pp. 99-120.

Bell, M. Pavitt, K. (1995) The development of technological capabilities. Trade, Technology and International Competitiveness. Economic Development Institute of the World Bank, pp. 69-100.

Becker. G. (1962) Investment in Human Capital: A Theoretical Analysis. Journal of Political Economy, 70(5): pp. 9-49.

Beltagui, A. (2018) A design-thinking perspective on capability development: The case of new product development for a service business model. International Journal of Operations \& Production Management. Vol. 38 No. 4, pp. 1041-1060 Emerald Publishing Limited 01443577 DOI 10.1108/IJOPM-11-2016-0661

Burgelman, R.A. (1994) Fading Memories: A Process Theory of Strategic Business Exit in Dynamic Environments. Administrative Science Quarterly, 39: pp. 24-56.

Chandler, A.D., Jr. (1977) The Visible Hand. Cambridge, Mass. and London, England: The Belknap Press of Harvard University Press.

(1992) Organizational capabilities and the economic history of industrial enterprise. Journal of Economic Perspectives, 6(3): pp. 79-100.

Christensen, J.F. (1995) Asset profiles for technological innovation. Research Policy, 24(5): pp. 727-745.

Coase, R. (1937) The nature of the firm. Economica, 4(16): pp. 386-405.

Darawong, C. (2018) Dynamic capabilities of new product development teams in performing radical innovation projects. International Journal of Innovation Science. vol. 10 No. 3, pp. 333-349 Emerald Publishing Limited 1757-2223 DOI 10.1108/IJIS-07-2017-0060

Dosi, G. (1988) Sources, procedures and microeconomic effects of innovation. Journal of Economic Literature, 26(3): pp. 1120-1171.
Eisenhardt, K. M. (1989) Building Theories from Case Study Research. The Academy of Management Review, Vol. 14, No. 4 (October), pp. 532-550

Eisenhardt, K.; Martin, J. (2000) Dynamic capabilities: What are they? Strategic Management Journal, 21(10-11): pp. 105-121.

Fallon-Byrne, L.; Harney, B. (2017) Microfoundations of dynamic capabilities for innovation: a review and research agenda. Irish Journal of Management. V.36 (1) 21-31 DOI: 10.1515/ijm-2017-0004

Felin, T.; Powell, T. C. (2016) Designing Organizations for Dynamic Capabilities. California Management Review Vol. 58, No. 4 Summer University of California, Berkeley

Freeman, C. (1994) The Economics of Technical Changes. Cambridge Journal of Economics, 18: pp. 463-514.

Furtado, A.T.; Carvalho, R. Q. (2005) Padrões de Intensidade Tecnológica da Indústria Brasileira - um estudo comparativo com os países centrais. São Paulo em Perspectiva, 19(1): pp. 70-84.

Guan, J.; Ma, N. (2003) Innovative Capability and export performance of Chinese Firms. Technovation, 23 (9): pp. 737-747.

Hashim, N. A. B.; Raza, S.; Minai, M. S. (2018) Relationship Between Entrepreneurial Competencies And Small Firm Performance: Are Dynamic Capabilities The Missing Link? Academy of Strategic Management Journal v.17, n.2.

Helfat, C.E.; Peteraf, M.A. (2003) The dynamic resource-based view: Capacidade lifecycles. Strategic Management Journal, Special Issue 24: pp. 997-1010.

Krzakiewicz, K.; Cyfert, S. (2017) Dynamic capabilities in strategic choice processes within organisations. Management. Vol. 21, No. 1. DOI: 10.1515/manment-2015-0077

Laaksonen, O.; Peltoniemi, M. (2018) The Essence of Dynamic Capabilities and their Measurement. International Journal of Management Reviews, Vol. 20, 184-205 DOI: 10.1111/ijmr.12122

Langlois, R.N. (1992)Transaction-cost economics in real time. Industrial and Corporate Change, 1: pp. 99-127.

Langlois, R.N.; Foss, N.J. (1999) Capability and Governance: The rebirth of production in the theory of economic organization. Kyklos.

Lall, S. Technological Capabilities and Industrialization. World Development, 20: pp. 165-186.

Lawson, B.; Samson, D. (2001) Developing Innovation Capability in Organizations: a dynamic capabilities approach. International Journal of Innovation Management, 5(3): pp. 377-400.

Lewin, A.Y.; Massini, S. (2003) Knowledge creation and organizational capability of innovating and imitating firms, in: TSOUKAS H.; MYLONOPOULOS, N. (ORG.) Organizations as knowledge Systems: Knowledge, Learning and Dynamic Capabilities, pp. 209-237. New York: Palgarve MacMillan. 
Madhok, A. (1996) The organization of economic activity: transaction costs, firm capabilities and the nature of governance. Organization Science, 7(5): pp. 577-590.

Massini, S.; Lewin, A.Y.; Greve, H.E. (2003) Innovators and Imitators: organizational reference groups and adoption of organizational routines.

Mayer, K; Salomon, R. (2006) Contract design as a firm Capability: an integration of learning and transaction cost perspectives. Academy of Management Review, 49(5): pp. 942-959.

Macphersona, A., Herbaneb, B., Jones, O. (2015) Developing dynamic capabilities through resource accretion: expanding the entrepreneurial solution space. Entrepreneurship \& Regional Development, Vol. 27, Nos. 5-6, 259-291, http://dx.doi.org/10.1080/08985626.2015.1038598

Mintzberg, H. (1973) The Nature of Managerial Work. Harper \& Row, New York.

Nelson, R. R.; Winter, S.G. (1982) An evolutionary theory of economic change. Cambridge: Harvard University Press.

OECD. (2003) Organization for Economic Co-operation and Development. Technology intensity definition. ISIC rev. 3, 2003. Available at: <http://www.oecd.org/dataoecd/43/41/48350231.pdf>. Accessed in 30.abr.2013.

Qaiyuma, S.; Wang, C. L. (2018) Understanding internal conditions driving ordinary and dynamic capabilities in Indian high-tech firms. Journal of Business Research 90, 206-214

Penrose, E. (1959) The Theory of the growth of the Firm. Oxford University Press.

Reichert, F. M.; Beltrame, R. S.; Corso, K.B.; Trevisan, M; Zawislak, P.A. (2011) Technological Capabilities Predictor Variables. Journal of Technology Management and Innovation, 2: pp. 41-50.

Richardson, G.B. (1972) The Organization of industry. Economic Journal, 82, pp. 883-896.

Schriber, S., Löwstedt, J. (2018) Managing asset orchestration: A processual approach to adapting to dynamic environments. Journal of Business Research 90 307-317 https://doi.org/10.1016/j.jbusres.2018.05.027

Schumpeter, J. (1912) The Theory of Economic Development. Harvard University Press, Cambridge.

Takahashi, A. R. W.; Bulgacov, S.; Bitencourt, C. C.; Kaynak, H. (2017) Expanding the Dynamic Capabilities View: Special Contributions. $R A E$, São Paulo, v. 57, n. 3, maio-jun, 209-214.

Teece, D.J. (1986) Profiting from Technological Innovation. Research Policy, 15: pp. 285-305.
(2006) Reflections on "Profiting from Innovation". Research Policy, 35: pp. 1131-114.

(2007) Explicating dynamic capabilities: The nature and microfoundations of (sustainable) enterprise performance. Strategic Management Journal, 28(13): pp. 1319-1350.

Teece, D. J.; Pisano, G.; Shuen, A. (1997) Dynamic Capabilities and Strategic Management. Strategic Management Journal, 18: pp. 509-533.

Teece, D.; Leih, S. (2016) Uncertainty, Innovation, and Dynamic Capabilities: An Introduction. California Management Review. Vol. 58, No. 4. Summer.

Tello-Gamarra, J.E.; Zawislak, P.A. (2013) Transactional capability: Innovation's missing link. Journal of Economics, Finance and Administrative Science, 18(34): pp. 2-8.

Terziovski, M. (2007) Building Innovation Capability in Organizations - An International Cross-Case Perspective. Imperial College Press.

Williamson, O. (1985) The Economic Institutions of Capitalism. Free Press, New York.

Winter, S. (2003) Understanding dynamics capabilities. Strategic Management Journal, 24(10): pp. 991-9995.

Yam, R.; Lo, W.; Tang, E.; Lau, A. (2011) Analysis of sources of innovation, technological innovation capabilities, and performance: An empirical study of Hong Kong manufacturing industries. Research Policy, 40 (3), pp. 737-747.

Yin, R. K. (2010) Estudo de Caso - Planejamento e Métodos, 4a ${ }^{\mathrm{a}}$ ed, Porto Alegre, Bookman.

Zahra, S.A.; Sapienza, H.J.; Davidson, P. (2006) Entrepreneurship and Dynamic Capabilities: A Review, Model and Research Agenda. Journal of Management Studies 43(4): pp. 917-955.

Zawislak, P.A.; Alves, A.C.; Tello-Gamarra, J.; Barbieux, D.; Reichert, F.M. (2012) Innovation Capability: From Technology Development to Transaction Capability. Journal of Technology Management \& Innovation, 7(2): pp. 14-27.

Zawislak, P.A.; Zen, A.C.; Fracasso, E.M.; Reichert, F.M.; Pufal, N.A. (2013) Types of Innovation in low-technology firms of emerging markets: an empirical study in Brazilian industry. RAI - Revista de Administração e Inovação, São Paulo, 10(1): pp. 04-27.

Zawislak, P.A.; Tello-Gamarra, J.; Alves, A.C.; Barbieux, D.; Reichert, F.M. (2013) 22 ${ }^{\text {nd }}$ International Conference on Management of Technology - IAMOT. Porto Alegre, 14-18 abril.

Zawislak, P.A.; Fracasso, E.M; Tello-Gamarra, J.E. (2013) Intensidade Tecnológica e Capacidade de Inovação de Firmas Industriais. XV Congresso da Associação Latino Ibero Americana de Gestão de Tecnologia, ALTEC. 


\section{APENDIX}

\section{PRELIMINARY ROUTE - IDENTIFYING COMPANY'S POSITION ON INNOVATION}

1. Make a brief account of the most striking facts for the company.

2. Is change important to your company?

3. How do changes occur in the company?

4. What makes people prefer your products rather than competing products?

5. Where do the ideas for innovation in the company come from?

6. Who is responsible for selecting the ideas on which the company will invest?

7. Is there any follow-up to the implementation of these ideas? If so, how does this follow up?

8. What is the percentage of gross sales of the company invested in research and development of products?

9. Name three important innovations that have occurred in the company's history. When they happened, in what way, how the idea came about.

10. Among the three innovations mentioned, what do you consider having contributed most to the evolution of the company's revenues?

11. Was this innovation a novelty for the company, for the industry, for the country or for the world?

12. Briefly describe what has changed in the company to achieve this innovation.

13. What made the company competitive before this change? And then?

\section{CAPABILITIES ROUTE - OBSERVING CHANGES}

1. Give a brief description of the changes that have taken place in the company from the Design Center.

2. How did you perceive the need for change?

3. Among the changes cited, which is the most important? Why?

4. Was there a need to hire staff? Why?

5. Was there a need to train staff? Why?

6. Was there a need to purchase equipment? Why?

7. Was it necessary to seek knowledge? In what way?

8. Has there been a change in routines? Describe it.

9. Was there a need to develop new processes?

10. Has anything changed in the relationship with suppliers?

11. Has the relationship changed with competitors?

12. How did the company stand with competitors after the creation of the Design Center?

13. Has there been any change in market share?

14. Has anything changed in the company's strategy?

15. Were there any changes in the company's administrative process?

16. Were the costs changed? What types of costs and in what way?

17. Was production efficiency affected? In what way?

18. Has the decision process been affected? In what way?

19. Was it necessary to establish new rules or rules from the Design Center? 
